\title{
Modern Urban Environment: Consumption, Game and Art*
}

\author{
Mikhail Dutsev \\ Department of Architectural Environment Design \\ Nizhny Novgorod State University of Architecture and Civil Engineering \\ Niznij Novgorod, Russia \\ E-mail: nn2222@bk.ru
}

\begin{abstract}
It is an obvious fact that today we witness formation of a many-sided and quite contradictory picture of interference of a social sphere, contemporary art and images of the urban environment. Consumer culture determines another way, as compared with traditional one, of sensing the works of art and interaction with the environment. Playing principles and playing behaviour are developed actively allowing a userrecipient to enter into a direct dialogue with the place in the totality of its contexts and functions. All this determine new conditions for creative activity of an architect, an artist, and a designer in the urban space which is acquiring features of integral architectural-artistic expression. The article places emphasis on the theoretic backgrounds and today's conditions for the development of this model, as well as gives an example of the artistic potential realization in the urban environment. The article contains photos made by the author.
\end{abstract}

Keywords-consumer society; installation; contemporary art; urban spaces; architectural environment; art integration

\section{INTRODUCTION}

At a recent 7 th Moscow Biennale of Contemporary Art in the framework of the curatorial project -Clouds $\leftrightarrows$ Forests" bu Yuko Hasegava my attention was drawn to one of the paintings by contemporary Indian artist Siji Krishnan titled Unknown family portrait" "Fig. 1", where people as a collective symbol of society were placed in some empty space... By doing this, the artist depicts each person with the attributes of his profession or every day activity as on a monumental frieze - as if the time has stopped. The general impression is completed by a traditional technique in which the work is painted. It seems that the image created by the artist may serve an exact illustration of today's uncertainty of the man in the surrounding world. The portrait demonstrates together the identity of every representative of the society, his individuality and anonymity, unity and loss of the society in general, as well as lack of ties with the place, anonymity

* The Reported study was Funded by Science and Technology Development State Program of the Russian Federation for years 2013-2020, Program of Fundamental Research of State Academies of Science for years 2013-2020, within the Program of Fundamental Researches of Ministry of Construction, Housing and Utilities of the Russian Federation and Russian Academy of Architecture and Construction Sciences; the Research Project 1.4.10. of the environment.

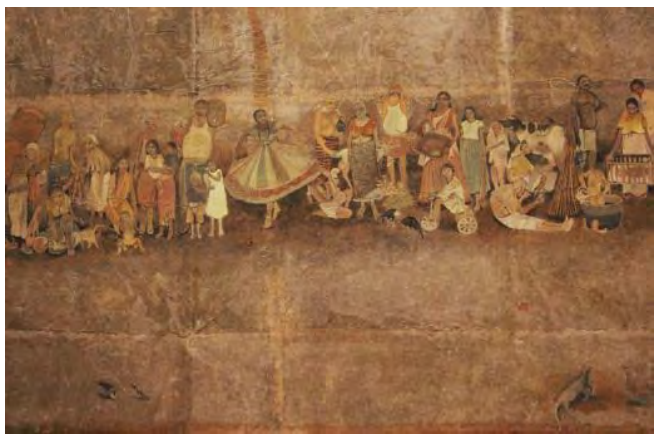

Fig. 1. Siji Krishnan (India). Unknown family portrait”, 2016, watercolor on rice paper. Fragment.

Issues of environment formation and its perception by a man are referred to those ones that are considered eternal and the most contradictory. One will never determine exactly what the architectural environment must be and define its artistic measurement. Traditions, style, fashion, social and cultural contexts will always reveal just some perspective of the entire real multidimensional integrity. The experience of describing and researching various aspects of urban environment shows that specialists in different fields of knowledge are mistaken almost the same way as nonprofessionals... The phenomenon of the environment, perhaps, is richer than the man's capability to view all of it from the given point of space and time!

Another view is also possible: our life is so deeply intertwined with the environment that there always exist certain proves and instinctive guessing" of its authenticity, its adequacy or non-correspondence to the cultural field and social moment. The environment is an integral part of human life.

Let us address the issue of artistic resources of a man's environment, if possible without separating esthetics from the aspects of the modern way of life. Are we capable to do so? Partly... The art will never be able to fit into the conventionalities of such a living approach", same, as we unlikely can and should not see all the impulses of an artist Let us leave it in the field of the mystery of creation. In the framework of our theme, let us try to see certain boundary 
conditions that determine the attitude to the city of an artist, an architect and its dweller or user.

The discussion of this theme is connected with the search for the answer not only to the questions what art is demanded by the city and in what forms, but also to important associated questions:

How is the image of a historic city maintained and compensated?

Has a modern city become an interlocutor?

Is there a new artistic image of the city environment, city life [1]?

What permits to preserve art qualities in the city?

\section{MODERN SOCIETY - CONSUMER SOCIETY}

Today's existence of the socium in a rather offensive but, perhaps, true format of a consumer society is an obvious fact. Let us refer to the sources.

Dictionaries give the following interpretation of the notion: Eonsumer society is a notion defining a set of social relations organized on the basis of an individual consumption principle. A consumer society is characterized by mass consumption of material benefits and formation of a corresponding system of values and aims". At the same time, the increase of free time predetermines appearance of an actual culture of leisure. Behind the above dry dictionary definitions there exists a whole layer of quite contradicting senses. On the one hand, mechanicalness and conventionality of behaviour, sort of predetermination of the choice, including esthetical, is noticed. On the other hand, just readiness itself of a person to refer to the cultural constituent of life in free time becomes important. And already owing to this, the artistic demand on the environment is formed. It is really so - sort of a consumer, market" mechanism of development of the environmental image.

Let us try to look at the features of the consumer society in their dynamics. The first general definition of the notion can be found in the works by German sociologist, philosopher, social psychologist and psychoanalyst, representative of the Frankfurt school E. Fromm. In his programme essay Man Alone" E. Fromm, primarily, speaks about different forms of alienation as a result of the orientation to the total consumption in the modern world. The scientist writes: Alienation is the fate of the individual under capitalism. By alienation I mean this type of life experience, when a person becomes a stranger to himself. It is as if he "shuts off", separates from himself. He ceases to be the center of his own world, the master of his actions; on the contrary, these actions and their consequences subjugate him, he obeys them and sometimes even turns them into a cult. In modern society, this alienation becomes almost allencompassing. It permeates a person's attitude to his work, to the objects he uses, extends to the state, to the people around him, to himself" [2].

According to these statements, a person now does not hear or see himself, does not detect his real personality, does not follow his own nature. What then become modern ideals and demands for the society? In what cultural environment does the contemporary world exist?

\section{A. “The Consumer Society”, J. Baudrillard, 1970}

The Consumer Society" [3] by J. Baudrillard (1970) gives a full and in many respects depressing picture of the contemporary world. This is, first of all, invasion of the mass media culture that backs up the main demands and principles, i.e. a certain desired substance, the feeling of happiness". Mass media and continuous production of pseudo-events" serve the non-stop promotion of goods -manufactured for happiness". The art in such a situation is a pop art that creates media, fashion, and kitsch.

Anyway, it would be interesting to understand how far the power of falsification" extends. How deeply does it affect the domain of feelings, the sphere of ideals formation? Is the demand for happiness included in this vicious circle? Immediately, the caustic utopia Generic City" [4] by R. Koolhaas is recollected, where this line reaches its extremes and is expressed by an architectural language.

In our opinion, the general critical tone is relevant but cannot be fully accepted, for the today's image of society and the way of its perception is the result of the natural evolution process.

\section{B. "The Society of the Spectacle", Guy Debord, 1967}

Possible answers to these rightful questions one may find in the well-known book by Guy Debord The Society of the Spectacle" [5] (1967), in which nowadays problems of the reality, its senses and meaning in the man's life are depicted mercilessly, in a thesis way; it also describes the development of ideas of social alienation and separation. The fact that the book has undergone several reprints during some decades with minimal revisions, to which the author points out, serves an extra prove of the topicality of the theses put forward by Guy Debord. The essence of the theory has not been changed, and even now, it continues to be viewed absolutely actual.

The conception of -spectacle" in the Guy Debord's theses is understood as a moment of significant substitution of life in its cultural and behavioural aspects. For a person the constant creation of performances has become his vital necessity, addiction that determines his perception of the reality". This is, actually, a deviation from the reality, but not artistic one that is always associated with the art, but in many respects compulsory, dictated by the market conditions. However, there are also more positive remarks, for example, the accurate pointing out to the rate of changes that requires constant change of decorations. Motion integrated in the performance is an essential function of the present.

\section{C. "Society of Leisure" and "Theory of Leisure"}

The notions -society of leisure" and theory of leisure" are actual, though quite contradicting characteristics of the present. Today there is a whole number of definitions close by meaning, mainly in the field of social sciences: -society of leisure" (M. Kaplan), epoch of leisure" threatening the 
humanity (D. Gabor), -eivilization of leisure" (J. Fourastié). According to J. Fourastié, at the existing model of the world leisure obtains more autonomy from labour and becomes an independent value. Let us elaborate on this thesis. It is true that we often observe appearance of the cult of free time manifesting in various forms, stylistics, and demanding participation of the art (new urban communities, entertaining infrastructure, festive events, youth festivals). With all this, there is a demand in intellectual, developing rest.

The city environment is used actively for leisure purposes in many ways: for a short break in work, brief rest during a working day, evening time after work, weekends, holidays, going out into nature (including natural landscapes in cities). No doubt, behind this list one may notice certain mechanics in the life of a modern person drawn into the continuous round of productive forces and goods. This is reality. Anyhow, even in these hopeless" conditions there exist encouraging premises, for example, a tendency of construction of museums, centres of art and cultural forums, increased attention to the environment. The phenomenon of contemporary media spaces should be mentioned particularly, which have become not only sources of information, but also places of meetings, free time spending, i.e. real bearers of cultural leisure.

\section{ARtistic IMAge ACtUAL MEANINGS}

...The image is a doctor of nostalgia, because thanks to it

the invisible becomes visible, the absent becomes present

Leone Battista Alberti

The Alberti's words point to a special reality created by an artist. Today, this super-reality in the aggregate of its images more often takes a tangible form to live in the city! Perhaps, for this, special conditions, certain transformations in the perception and initial addressing of the notion image" were needed. At one time, well-known philologist A.A. Potebnya, while speaking about the picturesque character of the art (primarily, poetry), underlined the role of the image in adaptation of the artistic world of the artist's product to the abilities of the recipient: -... image is something more simple and clear than explainable" [7]. The statement is in many aspects disputable, but it indicates an important circumstance - the compulsory initial presence of a recipient, the fact of his understanding.

Another, more exalted interpretation of the art's destination is given by Yu.M. Lotman in his work About the nature of art": It allows going through paths not taken, that is, what did not happen... And the history of the nonhappened is a great and very important history. And the art is always an opportunity to experience the non-lived, go back, replay and redo it again. It's an experience of what didn't happen. Or what may happen" [8]. The scientist backed up by the authority of a philosopher describes the history of human imagination existing together with the actual history, certain alternative life of the spirit. But further in the Lotman's arguments we notice an inevitable compromise at the crossing of these human histories: But the art envelops a huge sphere, and alongside there is semi-art, slightly art and entirely not-art. ...This is the sphere where the art flows into the not-art" [9]. It turns out that the nature of the artistic creation possesses both vectors, i.e. raising above the daily routine and moving towards the life of its recipient.

\section{A. Role of the Entertaining and Playing in the Modern World}

Closely approaching the problem of creative potential of the man especially in free time, beyond the deliberate creative work and professional activities, let us ask a question: What does -entertainment", amusement or game mean today? J. Huizinga in his well-known treatise Homo Ludens" (1938) [10] tied up the playing process with the affirmation of freedom and creativity in the life itself.

Let us draw our attention to five of the ten signs of playing introduced and studied by the researcher: voluntariness, freedom in play, a model of behaviour of the everyday life, an act of creation, limitation of space and time, aspiration for perfection. It follows from this list that play is considered an integral part of the real, full-value life. The author underlines that the veritable playing mentality (thinking) is an attribute of the developed society, but the surrogate of a play is imitation of freedom and creativity leading to civilization degradation.

Another vivid positioning of the studied phenomenon, no doubt, one may find in the novel The Glass Bead Game" of $\mathrm{H}$. Hesse (1942), where the highly canonized, elite game is described as a cultural tradition of generations.

Thanks to new urbanistics, the play concept has intelligently stepped in to the city. Jan Gehl in his book Eities for People" [11] (1971) offered methods of filling with life" urban space by introducing functions which once had been entirely domestic. In this case, a process of the city real emotional reopening by its inhabitants or visitors takes place. From the -xternal", the city turns into a space, which is much more close and home-like" for a person, at the same time it does not lose the benefits of public life: fullness, rapidity, and feeling of holiday.

Playing principles provide for several conditions: liberated creative activities of a free person that spring from his childhood; a code of rules cultivated through centuries and available just for the elite; finally, play as communication in the urban spaces as continuation of one's own household. It is important that all these aspects are characterized by integration of playing behaviour into everyday life of a person, which makes playing an important social factor.

Summing up certain intermediate results of the analysis of the modern system of values and mechanisms of perception, we notice quite a stubborn line of gaps in the living space of a person. As if there were several realities, materialized and imaginary. And it is an interesting thing, unlike the artistic realities accompanying the entire history of culture new realities bear marks of life substitutes, replacing" it. Certainly, this substitution is made by the man himself, which for the architectural environment becomes 
one of the main reasons of its degradation. The situation is not universal and straightforward, but can be considered as an obvious tendency, when fashion and simplified consumer communication prevail over a deep and multidimensional dialogue with the recipient.

On the other hand, a certain resource of perception has been actualized, a certain readiness of a person to react creatively to the messages of the environment, be interested in the city events, becoming their full participant. And this is also a part of consumer culture, but with the other, a positive sign. Today rapidity, dynamics of the environmental images are in demand, which cannot but change professional (or non-professional) approaches. Far from every architectural space is considered eternal and firm; it has to try various forms of mimicry, let art actions and events in or participate in a more complex logical game.

Play is one of the key positions in the given issue. Just the playing principles in a broad sense have become a mediator between the sublime and mundane. Play is multiform, and it includes a number of actual meanings:

- archetypical motives coming from childhood, role merits;

- theatrical and scenic interpretation of contexts;

- possibility of creative participation;

- living through the imaginary realities.

It is remarkable that almost all these positions may be looked at from opposite sides. For example, how far can a fictitious" reality thrusted on a customer by the conditions of commercial advantage differ from an experienced truly imaginary reality offered by an artist to the same recipient? Reaction of the recipient may be different: indifference, passive experience, creative interpretation, direct involvement. The large -eity game" has contradictory rules according to which the opposites may approach; for its full inclusion into the living space and continuation in time, all roles are needed!

\section{B. Technoimages, Post-postmodernism or Metamodernism (Postmillennialism, Trans-, Altermodernism)}

Postpostmodernism or metamodernism can give today's possible answers to the social turn in culture and art. Metamodernism is an effort to establish an actual large style in conditions when the canonic style thinking is in a deep crisis, simultaneously showing that change of paradigms is under way. Today a number of works has already been dedicated to this theme, and among them there is the book of Paul Auster City of Glass" (middle 1980s) or the article Eity as Landscape: post postmodern view of design and urban planning" (1995) by T. Turner, articles published in different years, including those written by Russian authors, for example, Post postmodern transit - architectural reflexes" by D. Fesenko.

Let us briefly describe characteristics of the notion useful for our theme. So, O. Mitroshenkov in the article -What will come instead of postmodernism?" (2013) points out the following key features of the metamodernism: virtualism, technoimages, glocalization, transsentimentalism [12].

It is important to explain the last position: transsentimentalism is a need to come back to the -obvious values" that give a person confidence: respect to ideals, striving for the generally accepted beauty and lyricism, feeling of belonging to the Big style", as well as nostalgic attitude to the heritage. According to Dutch cultural scientists Timotheus Vermeulen and Robin van den Akker, authors of the essay Notes on Metamodernism", a new phase in the history of culture was connected with the appearance in the culture of sincerity and openness in early 2000 s instead of irony and sarcasm of the 1990s in all spheres of the art.

In the article Paul Auster - Eity of Glass". To the issue of post postmodernism" O. Novikova emphasizes priority of playing behavior of a modern person [13]. If the postmodern play was based on irony and deconstruction, then the new playing strategy is more trusting - the author and recipient believe in the reality created by the play of the imagination: virtualism, certain naivety of the artistic perception. Communication and interactive reactions inside the virtuality turn the recipients into a collective subject of the social action - a dynamic fusion of the maker and audience creating in the network constantly modified images.

According to the terminology of French sociologist and culturologist A. Coquelin, such objects of -eollective intellect" constitute technoimages" (Coquelin, 2002), nonmaterial, flexible, unstable objects created in the network space by some users and changed by others" [14], the main role of which is self-organization of social interactions.

A doctrine of the play in earnest" is established, that has become reality of the design of architectural environment and actual design in general.

\section{SOCIETY - ARCHITECTURE - DESIGN, GOING TOWARDS EACH OTHER}

First of all, let us identify today's interactions of society, art and environment that all together form a certain matrix.

Society of:

- consumption

- performance

- leisure

Backgrounds traditionally included into the cultural field:

- history

- nature

- poetics

Demanded today and most available for a man" fundamentals:

- play

- theatre 
- dialogue

Images:

- images-ideals

- collective

- technoimages"

- $\quad$ virtual (invented, media).

Present condition of the professional and cultural field is not a simple, lengthy and long-awaited meeting at which reopening of the urban space is possible, as well as hope for understanding and acceptance of its constantly renewable image by a person appears. It is quite rightful to state that in the today's world the backgrounds as certain ideals of art ties and integration are actual and are needed again. Exactly these ties capable to restore the integrity are of our main interest! They may be called certain boundary backgrounds predetermining the meeting:

- traces of history and actual senses;

- functional process and poetry of space perception;

- collective opinion, creative work and the author's statement of an artist;

- civilization and natural principles;

- real environment, life and an artistic image.

A field of actual trends of architectural-artistic interactions related to the spiritual perception:

- image of history as a reference for saving the sole and spirit of the place";

- social entertainments - game and amusement;

- nature as an ideal -asis" to escape from civilization;

- art in the environment as a possibility to live through artistic images;

- theatre" as the world of illusion;

- virtuality beyond the boundaries of physical reality.

In modern conditions the professional community more often ask themselves a question, what the today's architectural environment of the city has become for specialists and its users, and what criteria it should meet. In this context the theme of artistic image of the city and its components, occurrence of new forms, methods, means and technologies, esthetic canons, their links and interpretations steps forward most urgently. In this respect it is useful to consider the actual urban environment in the problem field of the modern society, in the aspects of social attractiveness and most urgent needs of the man, including desires connected with the spiritual perception of reality.

Most important deep problems are: image of history, identity of historic structure and city substance, as well as mechanisms capable to save traditional functions in the renewed environment. In this context, history" presented by an architect or an artist can become the core and the symbol of saving the soul and spirit of the place.

An actual strategy of environment formation is maintaining continuous life of the city space in totality of residential, business and recreational functions. New urbanistics constantly applies to the moments of social activation and raise of environment attractiveness by means of play, entertainment and advertising - social amusements" drawing the recipient into an active dialogue. Functional and meaning overloading of the city finds its continuation in the image - - verloading". This line today is readily served by the design.

Certain antithesis of the previous tendency having affected absolute majority of large cities may be seen in the willingness to distance oneself from the products of civilization, total communication, bustling and emotional burning-out. Let us speak about some ways integrated differently in the creative activities of an architect.

First, most original reference is believed to be nature and its spontaneous perception, contemplation of elements and phenomena occurring in spite of man's will. Nature is an ideal -asis" for funning away", escape from the existing surroundings.

Art is another traditionally effective way to overcome reality without its actual destruction. Though constructive meaning of creative work today more often may be called into question... Actual practices create not only manifests and challenges to the present, but also real environmental conditions which the spectator or participant of a city event immerses in. It is important that the verge of an art-object, a work and an architectural form of the space practically disappears. Obviously, today this is the required and demanded resource of the modern city space. Art gives a possibility to transform the environment into an artistic image that may be actually lived through.

In continuation of the artistic-figurative line, the theatrical interpretation of environmental scenarios, generation of light effects, usage of media images have become especially urgent. The city-theatre" concept forms a world of illusions, kaleidoscopicity of architectural themes and styles, collage of materials, their properties and textures, play of transparencies and reflections. The power of the mentioned direction is confirmed by a number of authors' approaches and definitions: from the -dematerialization" by J. Nouvel, programme objects by J. Herzog and P. de Meuron to the flickering" by E. Diller and R. Scofidio.

Virtuality of the environment in various forms is apprehended today as a polar, but already prevailing direction permitting to make the bravest breakaway from the physical reality. If experiments with extra reality presuppose interaction with the living surroundings, then the extreme manifestations of the virtuality are oriented on creation of new alternative worlds. Basically, this is a continuation of the visionary designing or a variety of the paper" architecture -stepped over" the last frameworks assigned by the graphic material. 
The above review shows that a new society-oriented artistic-esthetic platform of architectural and environmental design is being formed in the cities, and best samples demonstrate a spectrum of modern style solutions and individual approaches of the authors. The actual art possesses an independent creative potential, performing brave interventions in the city space. All this establishes a vast, but most contradictory -set" of resources that need description, understanding, and systematization.

Certainly, along with mass, popular genres of environmental creativity there exists another pole represented by heartfelt things implying self-absorbed contemplation and simultaneously openness for public.

\section{A. Anselm Kiefer - The Seven Heavenly Palaces, Pirelli Hangar Bicocca in Milan, 2004-2015}

In the scale synthetic work The Seven Heavenly Palaces" "Fig. 2" the author's paintings in a great space adjoin with constructions, stones and sand. Though the former manufacturing space of a shop of the locomotive repair plant is now a free continuation of the city space, it has not been included directly into the city environment, but constitutes a black box" preserving a detached artistic world. The -site of specifics" genre allows referring to the contexts of the place being railway transfer junction.

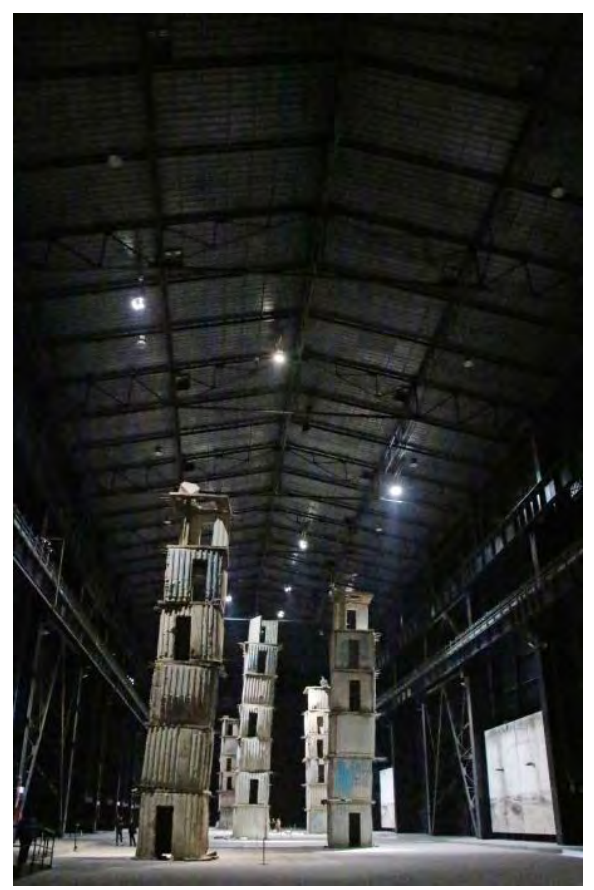

Fig. 2. Anselm Kiefer (Germany). The Seven Heavenly Palaces-Pirelli Hangar Bicocca in Milan. 2004-2015.

All this brings a visitor (who may enter the place absolutely freely, without any restriction) into another reality formed by seven towers resembling a post-apocalypses picture or slums of poor districts. The story not only common to all mankind, but also personal one lived by the author through mystic, sacral images in a real space appear before us. Here the author takes chances to share his innermost world and the idea of spiritual rising on the basis of the texts of the Hebrew scripture of the IV-V centuries with an occasional passer-by. The idea of construction of a heaven city" confronts with war violence and destructions.

Anyhow, we should not forget that an important feature of the genre is unlimited understanding and free selection of scenarios of behaviour. Any person who enters the room has the full right to interpret what he sees in his own way, to choose a painting or a -sculpture", to stay long or just pass by, to read an annotation, to ask for an explanation or to sink into his own thoughts. In this respect, the whole installation is a deliberation about capabilities of spirit in the routine of the everyday life.

\section{CONCLUSION}

In conclusion we may focus on the key, vectordetermining moments which help develop further this theme.

Primarily, this is the issue of art's boundaries". The statement itself looks incorrect, but exactly nowadays the crossing of various, basically, disciplinary boundaries places an artist in a difficult situation [15]. Becoming targer" itself, art risks to exhaust, dissolve or disappear at all...

The second aspect is connected with the problem of authorship and collective co-working, performed in time and in perspective... At all obvious orientation to social needs and inclusion of consumer motives, dialogue and so on, for culture in general forms of author's personal statement, realization of the artist's world are essential.

Finally, the third, promising perspective addresses to the re-establishing of ties and commence of approaching the consumer world and the world of free creative work. In some examples such a meeting takes place!

Thus, the article makes an effort to describe approximate contours of a possible meeting of the contemporary society with its specific features, merits and demerits and the art with its many faces, including preservation and refraction of those its merits which remain culture's property and form it's not passing value.

The article was prepared under the research at the expense of the State Program of the Russian Federation "Development of Science and Technology" for 2013-2020 in the framework of the Plan of Fundamental Scientific Research of the Ministry of Construction of Russia and RAASN, topic 1.4.10. "Artistic potential of modern city space".

\section{REFERENCES}

[1] M. Dutsev. Architecture at its boundary. Artistic potential of an interval. Series: Advances in Social Science, Education and Humanities Research: Proceedings of the 2017 International Conference on Art Studies: Science, Experience, Education (ICASSEE 2017) / M. Dutsev [Electronic resource]. - Available at : https://www.atlantis-press.com/proceedings/icassee-17/25888441.

[2] E. Fromm Man Elone / E. Fromm. Trans. from Engl. by R Oblonskaya. - M. : Publishing house Foreign literature", 1966, No. 1, p. 230. 
[3] J. Baudrillard. The Consumer Society / J. Baudrillard. - M. : Cultural revolution, Republic, 2006. -269 p.

[4] Rem Koolhaas. Bigness, or the problem of large. Generic City. Junkspace / Translated by: Vizel M.; Sitar S.; Babitskaya V. M.: JSC Art Guide, 2015, p. 84.

[5] G. Debord. The Society of the spectacle : [selected articles] / G. Debord. - M. : Opustoshitel, 2017. - 220 p. - (Series «Extremum» (\#14).

[6] M. Gioni. My project, of course, not about occultism or spiritualism / M. Dioni// Iskusstvo, 2013, No. 2 (585), p. 73-74.

[7] A.A. Potebnya. From the notes on the theory of literature / A.A. Potebnya. - Kharkov, 1905, p. 314.

[8] Yu.M. Lotman. About the nature of art / Yu.M. Lotman and the Tartu-Moscow semiotic school. - M. : «Gnozis», 1994, - 560 p., p. 433.

[9] Ibidem. P. 435.

[10] J. Huizinga. Homo ludens. / J. Huizinga. - Preface and transl. from Dutch by D.V. Silvestrov. Comments, glossary by D.E. Kharitonovich. - SPb. : Ivan Limbakh publishing house, 2011. - 416 p. P. 314.

[11] J. Gehl. Cities for people / transl. from English by A. Taktonov Washington: Island Press, 2010. Moscow : Krost publishing house, 2012. $-276 \mathrm{p}$.

[12] O. Mitroshenkov. What will come instead of postmodernism?/ O. Mitroshenkov. - Available at : http://svom.info/entry/355-chto-pridetna-smenu-postmodernizmu/.

[13] O. Novikova. Paul Auster - City of Glass". To the issue of post postmodernism / O. Novikova. - Available at: http://newlit.ru/novikova/4458.html.

[14] O. Mitroshenkov. What will come instead of postmodernism?/ O. Mitroshenkov. - Available at : http://svom.info/entry/355-chto-pridetna-smenu-postmodernizmu/.

[15] M. V. Dutsev. Concept of art integration as an actual resource of modern architecture. Part 2. Artist-architect / M. V. Dutsev // Architecture and construction of Russia, 2018, No. 2, p. 8-17. 